\title{
Chronic kidney disease in patients with diabetes mellitus type 2 or hypertension in general practice
}

Victor van der Meer, H Petra M Wielders, Diana C Grootendorst, Joost S de Kanter, Yvo WJ Sijpkens, Willem JJ Assendelft, Jacobijn Gussekloo, Friedo W Dekker and Ymte Groeneveld

\author{
ABSTRACT \\ Background \\ The prevalence and severity of chronic kidney disease \\ (CKD) in primary care patients with diabetes or \\ hypertension is unknown. \\ Aim \\ To assess the prevalence and severity of CKD in patients \\ with diabetes and hypertension; and identify whether \\ age, sex, diabetes, and hypertension are associated with \\ CKD. \\ Design of study \\ Cross-sectional survey. \\ Setting \\ Two Dutch primary health care centres (15 954 enlisted \\ patients). \\ Method \\ Patients, aged $\geq 25$ years, with known diabetes type 2 \\ $(n=471)$ or hypertension $(n=960)$, were selected on 1 \\ October 2006. Initial screening uptake rates were \\ assessed from the electronic patient records, and \\ patients were invited when blood or urine measurements \\ were missing. The presence of albuminuria was \\ determined, glomerular filtration rate estimated, and \\ clinical characteristics extracted. \\ Results \\ Initial screening uptake rates were $93 \%$ and $69 \%$ for \\ diabetes and hypertension, respectively, and increased to \\ $97 \%(n=455)$ and $87 \%(n=836)$ after active invitation. \\ The prevalence of CKD was $28 \%$ in diabetes and $21 \%$ in \\ hypertension only. The presence of diabetes was \\ independently associated with albuminuria (odds ratio \\ [OR] 4.23; 95\% confidence interval $[\mathrm{Cl}]=2.67$ to 6.71 ), \\ but not with decreased estimated GFR (eGFR) (OR 0.75; \\ $95 \% \mathrm{Cl}=0.54$ to 1.04$)$. Age showed the strongest \\ association with decreased eGFR (OR 2.73; $95 \% \mathrm{Cl}=$ \\ 2.02 to 3.70 ).

\section{Conclusion} \\ In primary care, more than one-quarter of patients with \\ diabetes and about one-fifth of patients with \\ hypertension have CKD. The high prevalence justifies \\ longitudinal follow-up in order to evaluate whether \\ intensified cardiovascular risk management is beneficial \\ in this primary care population. \\ Keywords \\ diabetes; hypertension; kidney disease, chronic; \\ prevalence; primary care; screening.
}

\section{INTRODUCTION}

Chronic kidney disease (CKD), defined as either decreased glomerular filtration rate (GFR) or albuminuria, or both, carries a risk of cardiovascular morbidity and mortality and progression to endstage renal disease..$^{1-3}$

Diabetes and hypertension are major causes of CKD. ${ }^{4}$ Therefore, current international guidelines recommend yearly screening for CKD in patients with diabetes or hypertension. ${ }^{5,6}$ Although the prevalence of CKD stages 3-5 (defined as estimated GFR $<60 \mathrm{ml} / \mathrm{min}$ per $1.73 \mathrm{~m}^{2}$ ) in the adult primary care population is estimated to be $5-7 \%$, data on the prevalence of CKD in high-risk (that is, diabetes and hypertension) primary care patients are scarce..$^{7,8}$ Additionally, the prevalent stages of severity and

V van der Meer, MD, PhD, GP, Department of Public Health and Primary Care, Leiden University Medical Centre and Academic Primary Health Care Centre 'Stevenshof', Leiden, the Netherlands. HPM Wielders, MD, GP; WJJ Assendelft, $M D, P h D$, professor of general practice; J Gussekloo, $M D$, $P h D$, professor of general practice; Y Groeneveld, $M D, P h D$, GP, Department of Public Health and Primary Care; DC Grootendorst, PhD, epidemiologist; FW Dekker, $M D, P h D$, Department of Clinical Epidemiology, Leiden University Medical Centre, Leiden, the Netherlands. YWJ Sijpkens, MD, PhD, internist-nephrologist, Bronovo Hospital, The Hague, The Netherlands. JS de Kanter, MD, GP, Academic Primary Health Care Centre 'Stevenshof', Leiden, the Netherlands.

\section{Address for correspondence}

Dr Victor van der Meer, Department of Public Health and Primary Care, Leiden University Medical Centre, Postzone V0-P, PO Box 9600, 2300 RC Leiden, The Netherlands.

E-mail: v.van_der_meer@lumc.nl

Submitted: 13 January 2010; Editor's response: 9 March 2010; final acceptance: 4 May 2010.

(C)British Journal of General Practice 2010; 60: 884-890.

DOI: 10.3399/bjgp10X544041 
current treatment of CKD in primary care patients with hypertension or diabetes are unknown.

Compliance with screening for CKD by primary care providers is low. ${ }^{9}$ Data from 2001 to 2004 revealed that in the Netherlands only $33 \%$ of patients with hypertension or diabetes are screened yearly for serum creatinine, and only $10 \%$ of patients with diabetes are screened for albuminuria. ${ }^{9}$ Possibly, absence of scientific data on the prevalence of CKD in primary care patients with hypertension or diabetes may contribute to these low screening uptake rates and subsequent underdiagnosis and undertreatment.

Therefore, a survey was conducted among primary care patients that aimed to: assess the prevalence, severity and current treatment with angiotensinconverting enzyme (ACE) inhibitors or angiotensin receptor blockers of CKD in patients with diabetes or hypertension; and identify whether age, sex, diabetes, and hypertension are associated with albuminuria and decreased GFR.

\section{METHOD}

\section{Population}

Patient data were obtained from two primary healthcare centres (11 GPs) in Leiden, the Netherlands. In Dutch primary health care, each inhabitant is registered with a general practice. The two primary healthcare centres serve a total population of 15954 . For each registered patient, diagnoses are coded according to the International Classification of Primary Care (ICPC) in an electronic patient record. ${ }^{10}$ Patients were selected who were aged $\geq 25$ years with a known diagnosis of hypertension (ICPC code K86 hypertension uncomplicated or K87 hypertension complicated) or type 2 diabetes mellitus (ICPC code T90). Patients with type 1 diabetes, or with type 2 diabetes or hypertension under hospital-based subspecialty care were excluded.

\section{Design}

A cross-sectional survey was started in October 2006, using data in the electronic patient records compiled by family physicians. For the selected patients, assessments of serum creatinine and albumin-to-creatinine ratio in urine (the preferred measurement for the detection of albuminuria) within 15 months prior to the selection date were extracted. Next, if no assessments or only one assessment were present in the electronic patient record, patients were actively invited by post or telephone to visit the primary healthcare centre for screening of serum creatinine and albumin-to-creatinine ratio.

Data were collected on demographic and clinical characteristics regarding age, sex, duration of hypertension or diabetes, cardiovascular comorbidity, blood pressure, fasting plasma glucose, glycosylated

\section{How this fits in}

Chronic kidney disease is an independent risk factor for cardiovascular morbidity and mortality. The prevalence of chronic kidney disease in primary care patients with diabetes and hypertension, already at increased cardiovascular risk, is unknown. This study shows that more than one-quarter of patients with diabetes and about one-fifth of patients with hypertension have chronic kidney disease, which justifies intensified cardiovascular risk management in these patients.

haemoglobin, body mass index (BMI), and waist circumference. The last available measures within the previous 15 months were used in the analyses. Cardiovascular comorbidity was present when at least one ICPC code for cardiovascular disease was registered (Table 1). ${ }^{10}$ Data on current use of ACE inhibitor, angiotensin receptor blocker, and insulin were extracted from the electronic patient record.

\section{Measurements}

All clinical chemical analyses were performed by SCAL Medical and Diagnostic Centre, Leiden, the Netherlands. For the determination of albumin and creatinine, the Roche Integra 800 (Roche, Basel, Switzerland) was used. Serum creatinine was measured enzymatically in 2006 and was not IDMS (isotope dilution mass spectrometry) calibrated.

\section{Chronic kidney disease}

Chronic kidney disease (CKD) was defined in terms of kidney damage (albuminuria) and decreased kidney function (decreased estimated glomerular filtration rate [eGFR]). ${ }^{11}$ Albuminuria was defined as an albumin-to-creatinine ratio greater than $2.5 \mathrm{mg} / \mathrm{mmol}$ or $3.5 \mathrm{mg} / \mathrm{mmol}$ for men and women, respectively, on at least two occasions. ${ }^{12}$ Urine sample data were coded as missing if only one measurement was present. ${ }^{11}$ If two (or more)

\section{Table 1. Selected ICPC codes for} cardiovascular comorbidity.

\begin{tabular}{ll} 
ICPC & \\
code & Description \\
\hline K74 & Ischaemic heart disease with angina pectoris \\
\hline K75 & Acute myocardial infarction \\
\hline K76 & Ischaemic heart diseases without angina pectoris \\
\hline K77 & Heart failure \\
\hline K78 & Atrial fibrillation \\
\hline K89 & Transient cerebral ischaemia \\
\hline K90 & Stroke/cerebrovascular accident \\
\hline K91 & Atherosclerosis \\
\hline K92 & Peripheral vascular diseases \\
\hline
\end{tabular}


measurements were present, the most recent sample was used for analysis of the data.

The eGFR was calculated from the modification of diet in renal disease (MDRD) equation:

eGFR $=186 \times(\text { serum creatinine } \times 0.0113)^{-1.154} \times$ (age $)^{-0.203} \times(0.742$ if female $),{ }^{4}$ where eGFR is measured in $\mathrm{ml} / \mathrm{min}$ per $1.73 \mathrm{~m}^{2}$, creatinine is in $\mu \mathrm{mol} / \mathrm{L}$, and age in years.

The stage of CKD was determined by kidney function and the presence of albuminuria. Stage 1 and 2 required the presence of albuminuria plus eGFR of $\geq 90$ and $60-89 \mathrm{~mL} / \mathrm{min}$ per $1.73 \mathrm{~m}^{2}$, respectively. Stage 3, 4, and 5 were defined by an eGFR of 30-59, 15-29, and $<15 \mathrm{ml} / \mathrm{min}$ per $1.73 \mathrm{~m}^{2}$ (or dialysis) either with or without albuminuria, respectively. ${ }^{11}$

\section{Statistical analysis}

With regard to the first study objective (prevalence, severity, and current treatment of CKD), proportions among patients with hypertension only or with diabetes were calculated. Statistical differences between the two groups were calculated by twosample Student $t$-tests for continuous outcomes and Fisher's exact tests for dichotomous outcomes. Because patients with a double diagnosis of diabetes and hypertension have perhaps only been registered as having diabetes (ICPC T90) and not as having hypertension (ICPC K86 or K87), it was decided not to split the diabetes group into those with and without hypertension in the main analysis.

With regard to the second study objective (association of age, sex, diabetes, and hypertension

\section{Table 2. Age-sex profile of the study population. Percentages reflect proportion across the columns.}

\begin{tabular}{|c|c|c|}
\hline Age band, years & Male, $n(\%)$ & Female, $n(\%)$ \\
\hline $0-24$ & 2653 (33.7) & 2561 (31.7) \\
\hline $25-44$ & 2405 (30.5) & $2458(30.4)$ \\
\hline $45-64$ & 2179 (27.7) & 2276 (28.2) \\
\hline $65-74$ & $441(5.6)$ & 426 (5.3) \\
\hline$\geq 75$ & $199(2.5)$ & $356(4.4)$ \\
\hline Total & 7877 & 8077 \\
\hline
\end{tabular}

Table 3. Age-diabetes and age-hypertension profile of the study population.

\begin{tabular}{lccc} 
Age band, years & Sample, $n$ & Diabetes, $n(\%)$ & Hypertension, $n(\%)$ \\
\hline $0-24$ & 5214 & $9(0.17)$ & $7(0.13)$ \\
\hline $25-44$ & 4863 & $50(1.0)$ & $123(2.5)$ \\
\hline $45-64$ & 4455 & $311(7.0)$ & $738(16.6)$ \\
\hline $65-74$ & 867 & $112(12.9)$ & $272(31.4)$ \\
\hline$\geq 75$ & 555 & $119(19.8)$ & $258(46.5)$ \\
\hline Total & 15954 & $601(3.8)$ & $1398(8.8)$
\end{tabular}

with $\mathrm{CKD}$ ), logistic regression models for albuminuria (CKD stage 1 and 2) and decreased eGFR (CKD stage 3, 4 and 5), respectively, were used. Dichotomised values were used for age ( $\leq 65$ versus $>65$ years) and blood pressure (systolic blood pressure $\leq 140$ versus $>140 \mathrm{mmHg}$ ). The association of age with CKD was adjusted for sex and vice versa. The association of diabetes with CKD was adjusted for age, sex, and hypertension, and the association of hypertension with CKD adjusted for age, sex, and diabetes. All analyses were carried out with Stata (version 10.0 StataCorp).

\section{RESULTS}

The two primary healthcare centres had 10740 patients aged $\geq 25$ years (Tables 2 and 3 ). There were 471 patients $(4.4 \%)$ registered with type 2 diabetes and 960 patients (8.9\%) with hypertension only. Data on serum creatinine and albumin-to-creatinine ratio within 15 months prior to the selection date were initially available for 439 (93\%) and 666 (69\%) patients, respectively. After active invitation for screening of serum creatinine and albumin-tocreatinine ratio, data were available for $455(97 \%)$ and 836 (87\%) patients, respectively (Figure 1). Compared to patients with hypertension only who attended screening, the $13 \%$ of patients with hypertension only who did not attend screening for CKD had similar age $(P=0.99)$ and sex $(P=0.21)$, but more often had cardiovascular comorbidity $(28 \%$ versus $19 \%$, $P=0.024$ ) and less often used ACE inhibitors or angiotensin receptor blockers $(41 \%$ versus $54 \%$, $P=0.009$ ).

Demographic and clinical characteristics are listed in Table 4. The group of patients with diabetes had a mean age of 63 years; $51 \%$ were female. Of all patients with diabetes, $53 \%$ had registered comorbid hypertension. Patients with hypertension only had a mean age of 61 years; $57 \%$ were female. Cardiovascular comorbidity was more prevalent in patients with diabetes than in patients with hypertension only: $30 \%$ versus $19 \% \quad(P<0.001)$. Patients with diabetes had a higher BMl and waist circumference, but lower blood pressure than patients with hypertension only. Serum total cholesterol and low-density lipoprotein cholesterol levels were higher for patients with hypertension only than for patients with diabetes. About half of all patients in both groups used ACE inhibitors or angiotensin receptor blockers.

\section{Chronic kidney disease}

Table 5 shows the prevalence of albuminuria, eGFR rate strata, and CKD stages for the diabetes-only and hypertension-only groups. Albuminuria was present in $13.6 \%$ of the diabetes group and $3.6 \%$ of the 


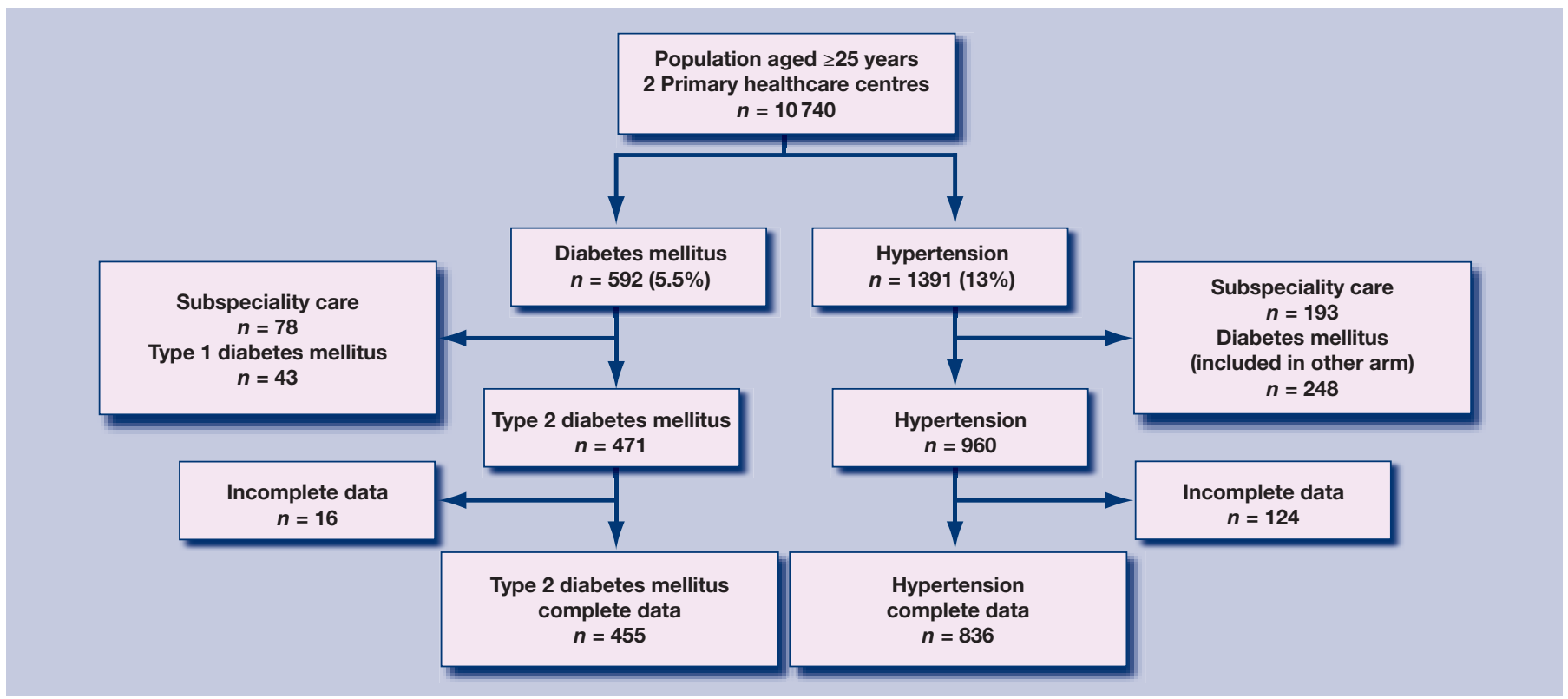

hypertension only group. The prevalence of CKD (stage 1-5) was $27.5 \%$ in the diabetes group and $21.1 \%$ in the hypertension-only group. Stage 3 was the most prevalent stage for both groups: $17.5 \%$ and $17.1 \%$ respectively.

Of the 62 diabetes patients with albuminuria, 47 (76\%) were currently treated with ACE inhibitor or angiotensin receptor blocker, compared to 29 of 30 $(97 \%)$ patients treated for albuminuria in the hypertension-only group. Of all 92 patients with albuminuria, $16(17 \%)$ were not treated with ACE inhibitor or angiotensin receptor blocker.

\section{Associations with kidney damage (albuminuria)}

Figure 2 displays associations of age, sex, diabetes, and hypertension characteristics with albuminuria. Diabetes had the strongest association with albuminuria; of all patients with diabetes, $13.6 \%$ had albuminuria compared to $3.6 \%$ of patients without diabetes (adjusted odds ratio [OR] 4.23; 95\% confidence interval $[\mathrm{Cl}]=2.67$ to 6.71 ).

Patients aged $>65$ years more often had albuminuria than patients aged $\leq 65$ years $(11.2 \%$ versus $4.9 \%$; adjusted $\mathrm{OR} 2.53 ; 95 \% \mathrm{Cl}=1.64$ to 3.89 ), and patients with hypertension more often than patients without hypertension (8.8\% versus 5.7\%; adjusted OR 1.63; $95 \% \mathrm{Cl}=1.04$ to 2.58$)$. The presence of albuminuria was similar for men and women $(7.9 \%$ versus $6.5 \%$; adjusted OR $1.35 ; 95 \% \mathrm{Cl}=0.88$ to 2.08 ).

\section{Associations with decreased kidney function (eGFR<60 $\mathrm{ml} / \mathrm{min}$ per $1.73 \mathrm{~m}^{2}$ )}

Figure 3 displays associations of demographic and clinical characteristics with decreased kidney function. Decreased eGFR was more present in older than younger patients: $25.8 \%$ in patients aged $>65$ years and $10.9 \%$ in patients aged $\leq 65$ years Figure 1. Flow diagram of selection procedure. (adjusted OR 2.73; 95\% Cl = 2.02 to 3.70). Men had decreased eGFR less often than women: $11.4 \%$ versus $20.2 \%$ (adjusted OR $0.54 ; 95 \% \mathrm{Cl}=0.39$ to $0.74)$. There were no statistically significant

Table 4. Demographic and clinical characteristics of primary care patients aged $\geq 25$ years with diabetes mellitus type 2 or with hypertension only.

\begin{tabular}{|c|c|c|c|}
\hline & $\begin{array}{l}\text { Diabetes mellitus } \\
\text { type } 2, n=455\end{array}$ & $\begin{array}{l}\text { Hypertension only } \\
\quad n=836\end{array}$ & $P$-value \\
\hline Age, years, mean (SD) & $63(13)$ & $61(12)$ & 0.004 \\
\hline Female sex, $n(\%)$ & $233(51)$ & $479(57)$ & 0.040 \\
\hline Duration diagnosis, years, mean (SD) & $7.2(5.4)$ & $6.5(4.8)$ & 0.027 \\
\hline Cardiovascular comorbidity,$n(\%)$ & $137(30)$ & $161(19)$ & $<0.001$ \\
\hline Diabetes with hypertension, $n(\%)$ & $239(53)$ & $\mathrm{n} / \mathrm{a}$ & $\mathrm{n} / \mathrm{a}$ \\
\hline Body Mass index, $\mathrm{kg} / \mathrm{m}^{2}$, mean (SD) & $29.7(5.5)$ & $27.7(4.5)$ & $<0.001$ \\
\hline \multicolumn{4}{|l|}{ Waist circumference, $\mathrm{cm}$, mean (SD) } \\
\hline Women & $100(12)$ & $93(13)$ & $<0.001$ \\
\hline Men & $104(14)$ & $101(11)$ & 0.008 \\
\hline \multicolumn{4}{|l|}{ Actual blood pressure, mmHg, mean (SD) } \\
\hline Systolic & $139(18)$ & $144(16)$ & $<0.001$ \\
\hline Diastolic & $81(8)$ & $84(9)$ & $<0.001$ \\
\hline Fasting plasma glucose, $\mathrm{mmol} / \mathrm{l}$, mean (SD & D) $7.2(2.0)$ & $5.3(0.7)$ & $<0.001$ \\
\hline Glycosylated hemoglobin, \% (SD) & $6.7(1.0)$ & $5.5(0.4)$ & $<0.001$ \\
\hline Total cholesterol, mmol/l, mean (SD) & $4.6(1.1)$ & $5.5(1.1)$ & $<0.001$ \\
\hline LDL cholesterol, mmol/l, mean (SD) & $2.5(0.9)$ & $3.3(1.0)$ & $<0.001$ \\
\hline \multicolumn{4}{|l|}{ Medication, $n(\%)$} \\
\hline ACEi/ARB & $228(50)$ & $452(54)$ & 0.18 \\
\hline Insulin & $88(19)$ & $\mathrm{n} / \mathrm{a}$ & $\mathrm{n} / \mathrm{a}$ \\
\hline No glucose lowering drugs & $132(29)$ & $\mathrm{n} / \mathrm{a}$ & $\mathrm{n} / \mathrm{a}$ \\
\hline
\end{tabular}

$A C E i=$ Angiotensin Converting Enzyme inhibitor. $A R B=$ Angiotensin receptor blocker. $L D L=$ Low density lipoprotein. $S D=$ standard deviation. at-tests and Fisher's exact tests for continuous and dichotomous outcomes, respectively. ${ }^{b}$ One or more International Classification of Primary Care (ICPC) codes for cardiovascular diseases (see Table 1). 
Table 5. Prevalence of albuminuria, estimated glomerular filtration rate (eGFR) and stages of chronic kidney disease.

\begin{tabular}{lccc} 
& $\begin{array}{c}\text { Diabetes mellitus } \\
\text { type } 2, n=455\end{array}$ & $\begin{array}{c}\text { Hypertension only } \\
n=836\end{array}$ & $P_{\text {-value }}$ \\
\hline Albuminuriab,$n(\%)$ & $62(13.6)$ & $30(3.6)$ & $<0.001$ \\
\hline eGFR, $n(\%)$ & & & $<0.001$ \\
$\geq 90 \mathrm{ml} / \mathrm{min} / 1.73 \mathrm{~m}^{2}$ & $137(30)$ & $146(18)$ & \\
$60-89$ & $238(52)$ & $540(65)$ & \\
$45-59$ & $64(14)$ & $128(15)$ & \\
$30-44$ & $14(3.1)$ & $18(2.2)$ & \\
$15-29$ & $2(0.4)$ & $4(0.5)$ & \\
$<15$ & 0 & 0 & $<0.001$ \\
\hline Chronic kidney disease, $n$ (\%) & & & \\
Stage 1: eGFR $\geq 90+$ albuminuria & $21(4.6)$ & $2(0.2)$ & \\
Stage 2: eGFR 60-89 + albuminuria & $25(5.5)$ & $24(2.9)$ & \\
Stage 3a: eGFR 45-59 & $64(14.0)$ & $128(15.3)$ & \\
Stage 3b: eGFR 30-44 & $14(3.1)$ & $18(2.2)$ & \\
Stage 4: eGFR 15-29 & $2(0.4)$ & $4(0.5)$ & \\
Stage 5: eGFR $<15$ or & 0 & 0 & \\
$\quad$ kidney replacement therapy & & & \\
\hline Total chronic kidney disease, $n$ (\%) & & $176(21.1)$ & \\
(stage 1-5) & $125(27.5)$ & & \\
\hline
\end{tabular}

eGFR = estimated glomerular filtration rate. ${ }^{a}$ Fisher's exact tests. ${ }^{b}$ Albumin-to-creatinine ratio $>2.5 \mathrm{mg} / \mathrm{mmol}$ for men, $>3.5 \mathrm{mg} / \mathrm{mmol}$ for women on at least two occasions.

Figure 2. Proportions of patients with albuminuria. Error bars indicate standard error of the mean. P-values were derived from the logistic regression models.

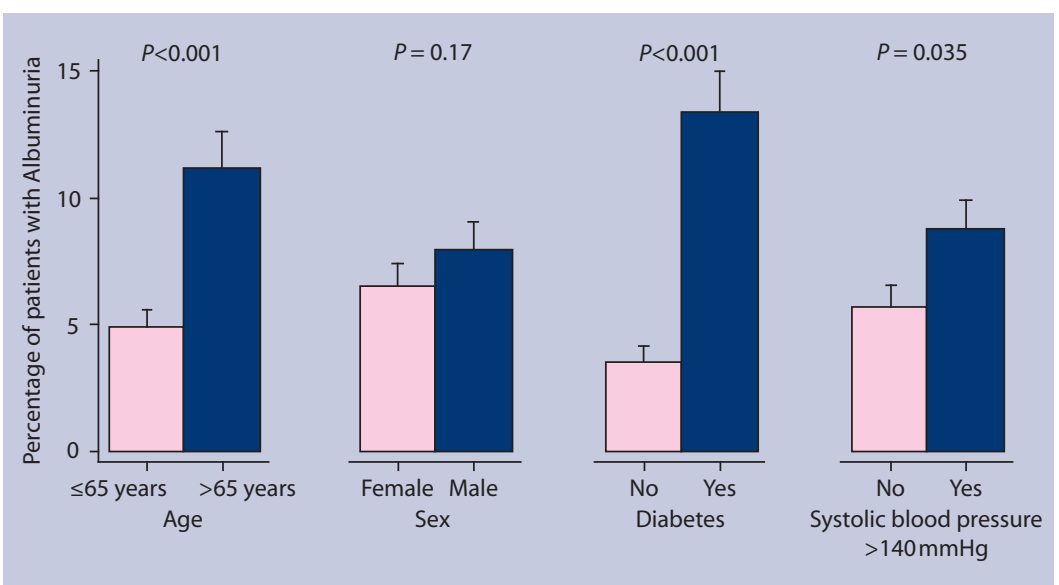

Figure 3. Proportions of patients with decreased estimated glomerular filtration rate (eGFR). Error bars indicate standard error of the mean. P-values were derived from the logistic regression models.

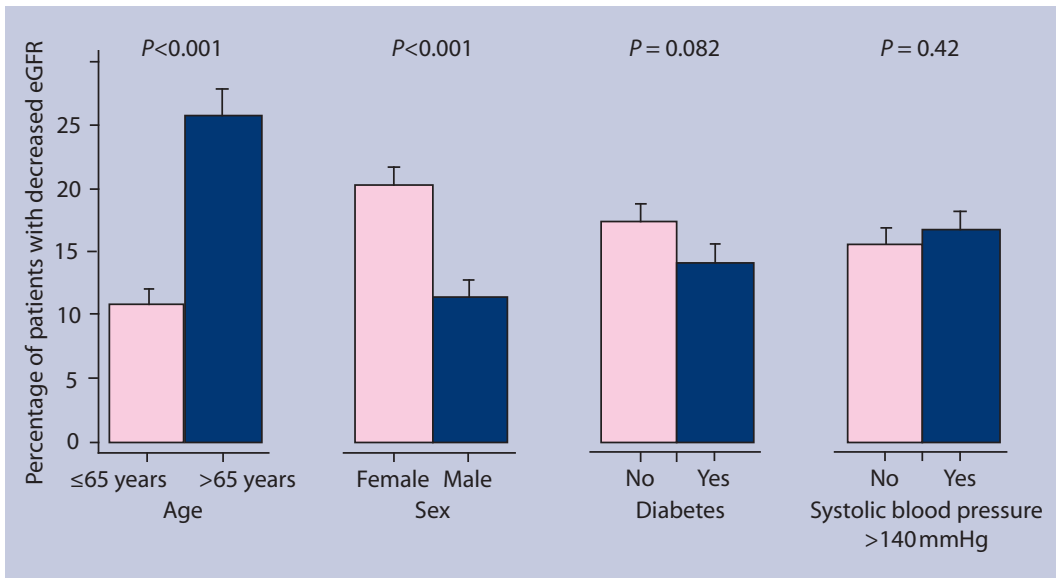

differences in decreased eGFR between patients with and without diabetes $(14.1 \%$ versus $17.5 \%$, respectively; adjusted OR $0.75 ; 95 \% \mathrm{Cl}=0.54$ to 1.04) and between patients with and without hypertension $(16.7 \%$ versus $15.4 \%$, respectively; adjusted OR $1.10 ; 95 \% \mathrm{Cl}=0.82$ to 1.48 ).

\section{DISCUSSION}

\section{Summary of main findings}

A cross-sectional survey was conducted among primary care patients with diabetes and hypertension in order to assess the prevalence and severity of CKD. The prevalence of CKD was $28 \%$ in patients with diabetes and $21 \%$ in patients with hypertension only; CKD stage 3 was the most prevalent stage $(17 \%)$ in both patient groups. The presence of diabetes was independently associated with albuminuria but not with decreased eGFR.

\section{Strengths and limitations of the study}

To the authors' knowledge, this is the first study that evaluates the prevalence and severity of CKD in primary care patients with diabetes or hypertension with the use of both serum creatinine assessments (to estimate GFR) and urine albumin excretion (to determine albuminuria). Screening uptake rates are high, providing valid prevalence estimates. The prevalence of stage 3 is greater than that of stages 1 and 2 . This is due to the definition of stage 1 and 2 requiring evidence of kidney damage (albuminuria), which is not required for stage 3 .

Some methodological issues need particular attention. First, the study is limited by its crosssectional design. There is no information available about the course of CKD, and factors that may predict rapid worsening of albuminuria or kidney function and subsequent cardiovascular events. Moreover, due to the relatively small samples in this study, associations between different severity levels (of both diabetes and hypertension) and CKD have not been studied. Follow-up data are required on how the identified associations with albuminuria (diabetes, age, and high current blood pressure) and decreased eGFR (age and sex) predict cardiovascular and renal outcome. Second, the study was performed in a limited number of primary healthcare centres, which are possibly not representative of all Dutch family physicians. The practices have affiliations with the Leiden University Medical Centre, which reflects increased awareness of GPs and staff of obtaining valid data and high screening uptake rates. However, this study shows that adherence and commitment to management guidelines with regard to diabetes, hypertension, and screening for CKD can lead to remarkably high screening uptake rates and a high proportion treated 
with ACE inhibitors/angiotensin receptor blockers in family practice.

Third, the study used the urine albumin-tocreatinine ratio as a measure of kidney damage. However, other measures are available such as urine sediment abnormalities and abnormal findings on imaging studies. Therefore the prevalence estimate of CKD stage 1-2 might be an underestimation, because some cases were missed.

\section{Comparison with existing literature}

This study evaluates the prevalence and severity of CKD in primary care patients with diabetes or hypertension with the use of assessments of serum creatinine as well as urine albumin. Some studies reported the prevalence of CKD stage $3-5$, but not stage 1-2 (albuminuria), in high-risk primary care patients. ${ }^{13,14}$ Others assessed the prevalence of CKD in the general population was about $5-7 \% .^{7,8}$ However, the validity of these prevalence estimates was impaired by incomplete eGFR and albuminuria data. ${ }^{7,8}$ In this study, the focus was on high-risk primary care patients (that is, with diabetes or hypertension) in order to identify the proportion of people with CKD in candidate risk groups. ${ }^{1,15}$ In patients with hypertension only, the screening uptake rate was lower (87\%) than in patients with diabetes (97\%). The patients with hypertension who did not attend screening had more cardiovascular comorbidity and used fewer ACE inhibitors and angiotensin receptor blockers. Therefore, the study finding of $21 \%$ CKD in patients with hypertension only might be an underestimation of the actual prevalence, since CKD is likely to be highly prevalent in the non-responders with cardiovascular comorbidity and possible undertreatment.

The definition and classification of CKD is made in relation to kidney damage (albuminuria) and decreased kidney function (GFR estimated by the MDRD formula). The distinction between kidney damage and decreased kidney function is important, because prevalence and risk management are different. The overall prevalence of albuminuria in the present study population was about $7 \%$. Albuminuria was much more prevalent in patients with diabetes (14\%) than in patients with hypertension only (4\%). Age and high systolic blood pressure were also associated with albuminuria. Since albuminuria predicts cardiovascular events, albuminuria is a guide to treatment with ACE inhibitors or angiotensin receptor blockers. ${ }^{4,16}$

There appears to be some progress in the use of ACE inhibitors/angiotensin receptor blockers in primary care diabetes patients: in the present study sample three-quarter of patients with diabetes and albuminuria were treated with ACE inhibitors/angiotensin receptor blockers compared with about one-third found in previous research. ${ }^{17}$ However, there is still room for improvement, not only regarding treatment of albuminuria with ACE inhibitors/angiotensin receptor blockers, but also regarding treatment of patients with diabetes and hypertension with antihypertensive medication to prevent CKD and cardiovascular disease. ${ }^{17}$

The prevalence of decreased kidney function (CKD stage $3-5$ ) was $18 \%$. In contrast to the association with albuminuria, diabetes and high systolic blood pressure were not associated with a decreased estimated GFR. However, statistically significant associations with decreased kidney function were found for age and sex. It is well recognised that kidney function declines with age, but decreased eGFR in older patients does not always reflect kidney disease and increased cardiovascular risk. ${ }^{18,19}$

Recent data show that cardiovascular morbidity and mortality in an older population aged $\geq 70$ years was only increased in eGFR levels below $50 \mathrm{ml} / \mathrm{min}$ per $1.73 \mathrm{~m}^{2}$, but not in levels between 50 and $60 \mathrm{ml} / \mathrm{min}$ per $1.73 \mathrm{~m}^{2,20}$ Cardiovascular management in older patients with decreased eGFR may, therefore, differ from cardiovascular management in younger patients with impaired renal function. ${ }^{21}$

Although the beneficial role of ACE inhibitors/angiotensin receptor blockers in nonproteinuric kidney disease is less well established, ${ }^{4}$ there are several reasons that justify identification, close follow-up, and intensified cardiovascular risk management of high-risk patients with decreased kidney function. First, decreased GFR is independently associated with the risk of death and cardiovascular events in young and middle-aged individuals. .,3,22 $^{2}$

Second, several adverse pathophysiological consequences such as anaemia, hyperphosphataemia, vitamin D deficiency, and hyperparathyroidism may need treatment or referral. Third, identification of decreased kidney function allows better dosing of drugs excreted by the kidney and avoidance of nephrotoxic drugs such as nonsteroidal anti-inflammatory drugs.

\section{Implications for future research}

To conclude, this study adds knowledge about the prevalence of CKD in high-risk patients. In the Dutch university-affiliated primary care centres, more than one-quarter of patients with diabetes and about onefifth of patients with hypertension have CKD. This high prevalence justifies longitudinal follow-up research in order to evaluate whether repeated measurements for CKD and intensified targeted cardiovascular risk management are beneficial in this 
primary care population that is already at increased risk for cardiovascular events.

\section{Funding}

None.

Ethical approval

Not applicable.

\section{Conflicts of interest}

The authors have stated that there are none.

\section{Acknowledgements}

Thanks to Bob Siegerink and Alexandra Bos for their efforts regarding the preparation of this manuscript. We also thank the staff members of the Stevenshof and Merenwijk Primary Health Care Centres, and John Souverijn of the SCAL Medical Diagnostic Centre, Leiden, The Netherlands for their collaboration.

\section{Discuss this article}

Contribute and read comments about this article on the Discussion Forum: http://www.rcgp.org.uk/bjgp-discuss

\section{REFERENCES}

1. Hallan SI, Dahl K, Oien CM, et al. Screening strategies for chronic kidney disease in the general population: follow-up of cross sectional health survey. BMJ 2006; 333(7577): 1047-1052.

2. Keith DS, Nichols GA, Gullion CM, et al. Longitudinal follow-up and outcomes among a population with chronic kidney disease in a large managed care organization. Arch Intern Med 2004; 164(6): 659-663.

3. Go AS, Chertow GM, Fan D, et al. Chronic kidney disease and the risks of death, cardiovascular events, and hospitalization. N Engl J Med; 351(13): 1296-1305.

4. National Kidney Foundation. K/DOQI clinical practice guidelines for chronic kidney disease: evaluation, classification, and stratification. Am J Kidney Dis 2002; 39(2 Suppl 1): S1-S266.

5. American Diabetes Association. Standards of medical care in diabetes. Diabetes Care 2009; 32 Suppl 1: S13-S61.

6. Graham I, Atar D, Borch-Johnsen K, et al. European guidelines on cardiovascular disease prevention in clinical practice: executive summary: Fourth Joint Task Force of the European Society of Cardiology and other societies on cardiovascular disease prevention in clinical practice (constituted by representatives of nine societies and by invited experts). Eur J Cardiovasc Prev Rehabil 2007; 14 Suppl 2: E1-40.

7. Richards N, Harris K, Whitfield M, et al. The impact of populationbased identification of chronic kidney disease using estimated glomerular filtration rate (eGFR) reporting. Nephrol Dial Transplant 2008; 23(2): 556-561.
8. De Lusignan $\mathrm{S}$, Chan $\mathrm{T}$, Stevens $\mathrm{P}$, et al. Identifying patients with chronic kidney disease from general practice computer records. Fam Pract 2005; 22(3): 234-241.

9. Nielen MMJ, Schellevis FG, Verheij RA. [Prevention of chronic kidney disease in primary care] in Dutch. Utrecht: NIVEL, 2006.

10. Lamberts $\mathrm{H}$, Wood M. International classification of primary care. Oxford: Oxford University Press, 1987

11. Levey AS, Corsh J, Balk E, et al. National Kidney Foundation practice guideline for chronic kidney disease: evaluation, classification, and stratification. Ann Intern Med 2003; 139(2): 137-147.

12. Viberti GC, Mogensen CE, Passa P, et al. St Vincent declaration: guidelines for the prevention of diabetic renal failure. In: Mogensen CE, ed. The kidney and hypertension in diabetes mellitus. Dordrecht: Kluwer Academic Publishers, 1994: 515-527.

13. Ravera M, Noberasco G, Re M, et al. Chronic kidney disease and cardiovascular risk in hypertensive type 2 diabetics: a primary care perspective. Nephrol Dial Transplant 2009; 24(5): 1528-1533.

14. Redón J, Cea-Calvo L, Lozano JV, et al. Kidney function and cardiovascular disease in the hypertensive population: the ERIC-HTA study. J Hypertens 2006; 24(4): 663-669.

15. Clase CM. Glomerular filtration rate: screening cannot be recommended on the basis of current knowledge. BMJ 2006 333(7577): 1030-1031.

16. Brantsma AH, Bakker SJL, De Zeeuw D, et al. Extended prognostic value of urinary albumin excretion for cardiovascular events. J Am Soc Nephrol 2008; 19(9): 1785-1791.

17. New JP, Middleton RJ, Klebe B, et al. Assessing the prevalence, monitoring and management of chronic kidney disease in patients with diabetes compared with those without diabetes in general practice. Diabet Med 2007; 24(4): 364-369.

18. Coresh J, Astor BC, Green T, et al. Prevalence of chronic kidney disease and decreased kidney function in the adult US population: Third national health and nutrition examination survey. Am J Kidney Dis 2003; 41(1): 1-12.

19. Roderick PJ, Atkins RJ, Smeeth L, et al. Detecting chronic kidney disease in older people; what are the implications? Age Ageing 2008; 37(2): 179-186.

20. Ford I, Bezlyak V, Stott DJ, et al. Reduced glomerular rate and its association with clinical outcome in older patients at risk of vascular events: secondary analysis. PLoS Med 2009; 6(1): e16.

21. Van Bemmel T, Woittiez K, Blauw GJ, et al. Prospective study of the effect of blood pressure on renal function in old age: the Leiden 85 Plus Study. J Am Soc Nephrol 2006; 17(9): 2561-2566.

22. Foley RN, Murray AM, Li S, et al. Chronic kidney disease and the risk for cardiovascular disease, renal replacement, and death in the United States Medicare population, 1998 to 1999. J Am Soc Nephrol 2005; 16(2): 489-495. 